\title{
Antibiotic Resistance of Staphylococcus spp. Isolated from Sewage in Manaus, Amazonas
}

\author{
Sabrine P. Nogueira, Suanni L. Andrade, Paulo F. C. Magalhães Jr and Rudi E. L. Procópio
}

\section{ABSTRACT}

\begin{abstract}
Staphylococcus spp. have become important human pathogens in recent decades due to the selection of resistant bacteria and the spread of their resistance genes in the environment. This study aimed to evaluate the resistance of Staphylococcus spp. obtained from sewage in the city of Manaus, Amazonas state, Brazil. The isolates were tested for susceptibility to antimicrobials using the Kirby-Bauer method for ampicillin, azithromycin, ciprofloxacin, clindamycin, chloramphenicol, erythromycin, gentamicin, oxacillin, cefoxitin, linezolid, penicillin, rifampicin, sulfazotrim, tetracycline and vancomycin. Among the strains isolated from sewage, the greatest resistance was observed for penicillin and oxacillin, with $100 \%$ of isolates resistant to these antibiotics. Some antibiotics had resistant and sensitive strains (ampicillin, clindamycin, erythromycin, cefoxitin, azithromycin). Staphylococcus spp. were identified as sensitive to ciprofloxacin chloramphenicol gentamicin linezolid sulfazotrim tetracycline, vancomycin, with no strain resistant to these antibiotics.
\end{abstract}

Keywords: Antibiotic, Resistance, Sewage, Staphylococcus.
Published Online: February 7, 2021

ISSN: 2593-8339

DOI: $10.24018 /$ ejmed.2021.3.1.597

\section{S. P. Nogueira}

Universidade do Estado do AmazonasUEA, Manaus, Amazonas, Brasil.

(e-mail: spn.med16@uea.edu.br)

S. L. Andrade

Universidade do Estado do Amazonas-

UEA, Manaus, Amazonas, Brasil.

(e-mail:slandrade@uea.edu.br)

P. F. C. Magalhães Jr

Universidade do Estado do Amazonas-

UEA, Manaus, Amazonas, Brasil.

(e-mail: pjunior@uea.edu.br)

R. E. L. Procópio*

Universidade do Estado do Amazonas-

UEA, Manaus, Amazonas, Brasil.

(e-mail: rprocopio@gmail.com)

*Corresponding Author

\section{INTRODUCTION}

Staphylococcus aureus is one of the main human pathogens, which can trigger a variety of infectious diseases, such as skin and soft tissue infections, endocarditis, osteomyelitis, bacteremia and lethal pneumonia. Infectious diseases are the second leading cause of human deaths worldwide [1]. In recent decades, due to the adaptation of bacteria and the use of large amounts of antibiotics, resistant $S$. aureus strains have been selected. The ability of Staphylococcus to acquire and/or develop resistance to antibiotics is well known, mainly due to the presence of mobile genetic elements (plasmids, transposons and bacteriophages), which play a fundamental role in the ability of $S$. aureus to adapt to environmental stresses, including exposure to antibiotics [2]. In addition to the traditional mechanisms of resistance, a special feature of the pathogenesis of Staphylococcus spp. is their ability to survive on biotic and abiotic surfaces by forming biofilms. The formation of biofilm has the function of protecting bacteria in hostile environments. The bacteria inside the matrix are more resistant to the host's immune response and to antimicrobial agents than free bacteria, requiring a much higher concentration of antibiotics to eliminate them [3]. The ability of bacteria to develop and acquire antimicrobial resistance has quickly led to the emergence of multidrug-resistant strains, such as methicillin-resistant $S$. aureus (MRSA). These strains have become endemic in most hospitals worldwide. Strains have also been reported to be resistant to vancomycin (VRSA) [4]. The importance of Staphylococcus as a pathogen lies not only in human populations, but also in the environment. The frequent use of antibiotics has contributed to the spread of resistant bacteria or their resistance genes in the environment. In addition, most of the antibiotics consumed are not absorbed and can end up in wastewater, which can infect people with resistant bacteria [5]. Hence, there is a need to monitor Staphylococcus resistance, as well as the appropriate use of antibiotics, to minimize the prevalence of antimicrobial resistance.

\section{MATERIALS AND METHODS}

\section{A. Bacterial Samples}

Five milliliters of sewage water was collected in Manaus, Amazonas ( $3^{\circ} 08^{\prime} 10.3$ "S $60^{\circ} 00^{\prime} 33.7^{\prime \prime} \mathrm{W}$ - Google). Strains of Staphylococcus spp. were cultured in Baird-Parker Agar medium (Merck) for 24 hours at a temperature of $35^{\circ} \mathrm{C}$, according to [6]. Colonies with typical morphology on BairdParker Agar supplemented with egg yolk tellurite emulsion were selected and subjected to Gram staining. The strains were grown at the ESA / UEA Microbiology Laboratory at 
$35{ }^{\circ} \mathrm{C}$ in soybean triptych broth (TSB) for antibiotic resistance tests.

\section{B. In vitro Susceptibility to Antimicrobials}

For the susceptibility test, the Kirby-Bauer disk diffusion method (Polisensidisc-DME), one of the most widely used antimicrobial sensitivity tests, was employed, with the following antibiotics and concentrations: ampicillin-AMP $10 \mu \mathrm{g}$; azithromycin-AZI $15 \mu \mathrm{g}$; ciprofloxacin-CIP $05 \mu \mathrm{g}$; clindamycin-CLI $02 \mu \mathrm{g}$; chloramphenicol-CLO $30 \mu \mathrm{g}$; erythromycin-ERI $15 \mu \mathrm{g}$; gentamicin-GEN $10 \mu \mathrm{g}$; oxacillinOXA $01 \mu \mathrm{g}$; cefoxitin-CFO $30 \mu \mathrm{g}$; linezolid-LNZ $30 \mu \mathrm{g}$; penicillin G-PEN $10 \mu \mathrm{g}$; rifampicin-RIF $05 \mu \mathrm{g}$; sulfazotrimSUT $25 \mu \mathrm{g}$; tetracycline-TET $30 \mu \mathrm{g}$; and vancomycin-VAN $30 \mu \mathrm{g}$. The medium used was Mueller-Hinton agar (Himedia), which is the recommended standard for antimicrobial susceptibility testing.

The disk-diffusion method was carried out according to [7]. With the aid of a bacteriological loop, the Staphylococcus isolates were inoculated in $5 \mathrm{ml}$ of TSB broth (Himedia), and grown at $35{ }^{\circ} \mathrm{C}$ and $150 \mathrm{rpm}$ for 24 hours. After growth, a sterile swab was introduced into the tube. The inoculation was done in the form of streaks on the surface of the MuellerHinton agar in three directions. Then the discs were applied to the surface of the culture medium and incubated for 24 hours at $37^{\circ} \mathrm{C}$.

\section{Reading the Plates and Interpreting the Results}

After 24 hours of incubation, the plates were evaluated to read the inhibition halo, measured with a ruler. The diameters of the inhibition halos were interpreted according to the criteria recommended by [8].

\section{RESUlTS}

It was possible to isolate several strains with dark coloring in the Baird-Parker medium, characteristic of Staphylococcus spp. Nine isolates of Staphylococcus spp. were selected and evaluated. The pattern of antibiotic resistance among the isolates varied widely, as shown in Table 1. The highest resistance was observed for penicillin and oxacillin, with $100 \%$ of isolates resistant to these antibiotics. Some antibiotics had resistant and sensitive strains (ampicillin, clindamycin, erythromycin, cefoxitin and azithromycin). The UEA-07 isolate showed resistance to the largest number of antibiotics (40\%), being resistant to six of the fifteen tested antibiotics (clindamycin, azithromycin, ampicillin, erythromycin, oxacillin and penicillin).

According to the results of the sensitivity tests, all Staphylococcus isolates were identified as sensitive to ciprofloxacin, chloramphenicol, gentamicin, linezolid, sulfazotrim, tetracycline and vancomycin, with no strain resistant to these antibiotics (Fig. 1). For azithromycin and erythromycin, there was large variation between the isolates, with some sensitive and others resistant. For gentamicin and rifampicin, although there were no resistant strains, some strains were intermediate, as can be seen in Fig. 1 .

The UEA-03 isolate was able to grow in the presence of erythromycin, despite forming an inhibition halo (Fig. 2), showing that Staphylococcus spp. are capable of acquiring resistance to certain antibiotics easily. For clindamycin, the inhibition halo was not as well defined as in the other antibiotics, as can be seen in Fig. 2.

TABLE I: PATTERNS OF ANTIMICROBIAL RESISTANCE OF SELECTED STAPHYLOCOCCUS SPP

\begin{tabular}{|c|c|c|c|c|c|c|c|c|c|c|c|c|c|c|c|}
\hline $\begin{array}{c}\text { Antibiotics } \\
\text { Isolates }\end{array}$ & $\begin{array}{l}A M P \\
10 \mu \mathrm{g}\end{array}$ & $\begin{array}{c}A Z I \\
15 \mu \mathrm{g}\end{array}$ & $\begin{array}{l}C I P \\
5 \mu \mathrm{g}\end{array}$ & $\begin{array}{l}C L I \\
2 \mu \mathrm{g}\end{array}$ & $\begin{array}{l}C L O \\
30 \mu \mathrm{g}\end{array}$ & $\begin{array}{c}E R I \\
15 \mu \mathrm{g}\end{array}$ & $\begin{array}{l}G E N \\
10 \mu \mathrm{g}\end{array}$ & $\begin{array}{c}O X A \\
1 \mu \mathrm{g}\end{array}$ & $\begin{array}{l}C F O \\
30 \mu \mathrm{g}\end{array}$ & $\begin{array}{l}L N Z \\
30 \mu \mathrm{g}\end{array}$ & $\begin{array}{l}P E N \\
10 \mu \mathrm{g}\end{array}$ & $\begin{array}{l}R I F \\
5 \mu \mathrm{g}\end{array}$ & $\begin{array}{l}S U T \\
25 \mu \mathrm{g}\end{array}$ & $\begin{array}{c}T E T \\
30 \mu \mathrm{g}\end{array}$ & $\begin{array}{l}V A N \\
30 \mu \mathrm{g} \\
\end{array}$ \\
\hline$U E A-01$ & $\underline{18}$ & $\underline{14}$ & 30 & $\mathrm{R}$ & 28 & $\underline{17}$ & $\underline{14}$ & $\mathrm{R}$ & 17 & 35 & 13 & $\underline{17}$ & 36 & 28 & 25 \\
\hline$U E A-02$ & $\overline{15}$ & $\overline{10}$ & 40 & $\mathrm{R}$ & 40 & $\underline{18}$ & $\overline{30}$ & $\mathrm{R}$ & 34 & 40 & $\mathrm{R}$ & $\overline{40}$ & 25 & 40 & 26 \\
\hline$U E A-03$ & 10 & 22 & 25 & $\underline{17}$ & 25 & 30 & 26 & $\mathrm{R}$ & 27 & 30 & $\mathrm{R}$ & 22 & 25 & 30 & 18 \\
\hline$U E A-04$ & 10 & $\underline{14}$ & 44 & 10 & 40 & 12 & 31 & $\mathrm{R}$ & 36 & 45 & $\mathrm{R}$ & 32 & 26 & 40 & 30 \\
\hline$U E A-05$ & $\mathrm{R}$ & $\underline{16}$ & 36 & 14 & 38 & $\underline{15}$ & 38 & $\mathrm{R}$ & 38 & 40 & 20 & 36 & 27 & 40 & 30 \\
\hline$U E A-06$ & $\underline{19}$ & $\underline{14}$ & 24 & $\mathrm{R}$ & 24 & $\underline{17}$ & $\underline{14}$ & $\mathrm{R}$ & 20 & 38 & 14 & 20 & 33 & $\underline{18}$ & 24 \\
\hline UEA-07 & $\bar{R}$ & $\overline{10}$ & 34 & $R$ & 42 & $\overline{12}$ & $\overline{30}$ & $R$ & 30 & 40 & $R$ & 36 & 24 & $\overline{44}$ & 24 \\
\hline UEA-08 & $\mathrm{R}$ & $\underline{14}$ & 36 & $\mathrm{R}$ & 30 & $\mathrm{R}$ & 30 & $\mathrm{R}$ & 30 & 44 & $\mathrm{R}$ & 34 & 26 & 40 & 25 \\
\hline UEA-09 & $\mathrm{R}$ & $\underline{15}$ & 36 & $\mathrm{R}$ & 38 & $\underline{15}$ & 34 & $\mathrm{R}$ & 32 & 44 & $\mathrm{R}$ & 34 & 24 & 36 & 30 \\
\hline Resistant & $\mathrm{R} \leq 17$ & $\mathrm{R} \leq 13$ & $\mathrm{R} \leq 15$ & $\mathrm{R} \leq 14$ & $\mathrm{R} \leq 12$ & $\mathrm{R} \leq 13$ & $\mathrm{R} \leq 12$ & $\mathrm{R} \leq 17$ & $\mathrm{R} \leq 21$ & $\mathrm{R} \leq 20$ & $\mathrm{R} \leq 28$ & $\mathrm{R} \leq 16$ & $\mathrm{R} \leq 10$ & $\mathrm{R} \leq 14$ & $\mathrm{R} \leq$ \\
\hline Sensitive & $\mathrm{S} \geq 24$ & $\mathrm{~S} \geq 18$ & $\mathrm{~S} \geq 21$ & $\mathrm{~S} \geq 21$ & $\mathrm{~S} \geq 18$ & $\mathrm{~S} \geq 23$ & $\mathrm{~S} \geq 15$ & $\mathrm{~S} \geq 18$ & $\mathrm{~S} \geq 22$ & $\mathrm{~S} \geq 21$ & $\mathrm{~S} \geq 29$ & $\mathrm{~S} \geq 20$ & $\mathrm{~S} \geq 16$ & $\mathrm{~S} \geq 19$ & $\mathrm{~S} \geq$ \\
\hline
\end{tabular}

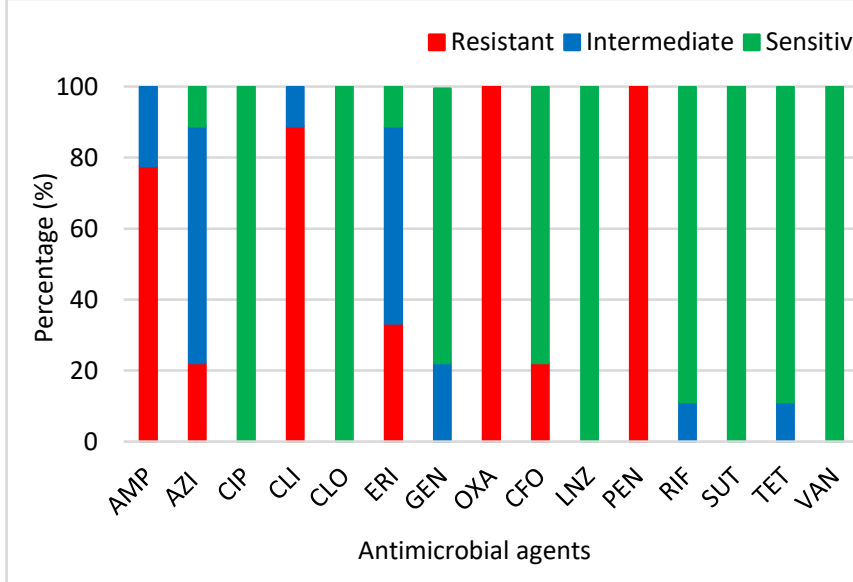

Fig. 1. Antibiotic susceptibility and resistance of Staphylococcus isolates.

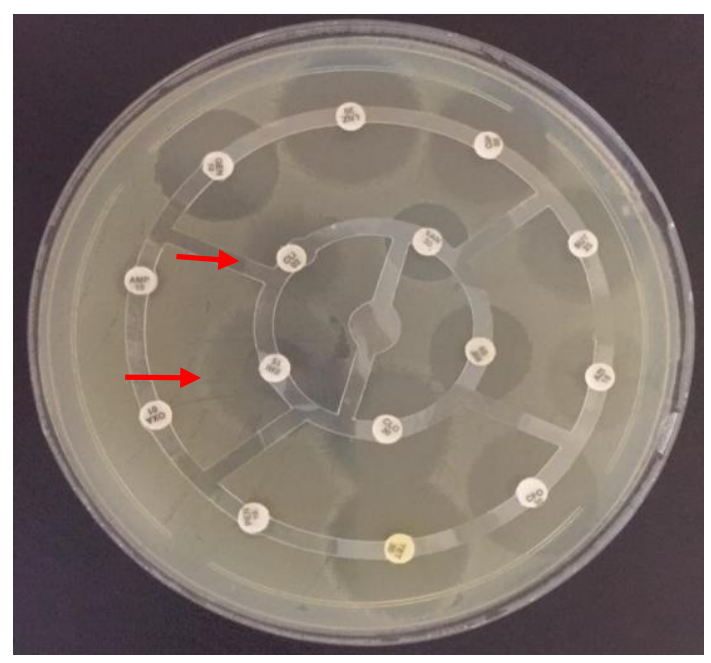

Fig. 2. Sensitivity of the UEA-03 isolate to the tested antibiotics. 


\section{DisCUSSION}

The spread of antibiotic resistance of the Staphylococcus genus has become worrying because of its presence in in wastewater, mainly in the sewers of large cities. The use of antibiotics is one of the main resistance inducers, because part of the antibiotic used reaches the environment with activity intact, promoting the selection of resistant microorganisms [9].

Similar to the results found in the present study, other authors have also reported a high rate of resistance to $\beta$ lactams. Assessing the prevalence of Staphylococcus spp. and $S$. aureus in a dental clinic, [10] observed that $79.5 \%$ of $S$. aureus isolates showed $\beta$-lactamase production, conferring resistance to ampicillin and erythromycin. [11], evaluating the microbiological quality of lettuce salads in restaurants, found 30 Staphylococcus spp. isolates, with respective resistances to penicillin $(56.7 \%)$, oxacillin $(46.7 \%)$ and erythromycin $(26.7 \%)$. [12] evaluating the patterns of antibiotic resistance of $S$. aureus in dairy herds in South Africa, observed a higher prevalence of resistance to penicillin $\mathrm{G}$ and ampicillin, probably due to the fact that these antibiotics of the beta-lactam class are the most used as intramammary remedies in that country. Although a high level of clindamycin-resistant isolates has been observed, few studies have reported this resistance. [13] evaluated the profile of antibiotic resistance in Staphylococcus isolated from a stream in Southern Brazil. Erythromycin resistance was found in $37.50 \%$ of the strains, followed by $27.27 \%$ to penicillin, $12.50 \%$ to clindamycin, $6.81 \%$ to trimethoprimsulfamethoxazole, $5.68 \%$ to chloramphenicol and $2.27 \%$ to norfloxacin, while none of the strains investigated showed resistance to gentamicin and ciprofloxacin. These findings are similar to ours in Manaus.

Bacterial infections remain a challenging public health problem due to the emergence and spread of multidrugresistant strains, such as $S$. aureus resistant to vancomycin, which is the main antibiotic used to treat resistant strains [14]. In this study, no vancomycin-resistant strain was observed. This can be attributed to its relatively restricted use in Brazil. Knowledge and monitoring of local resistance patterns are essential for the formulation of effective strategies for the treatment of bacterial infections. In addition, overuse of antibiotics causes the emergence of bacterial resistance and increases health costs and sepsis-related deaths.

Some Staphylococcus strains are considered inhabitants of the normal microbiota, and do not have all the virulence factors found in S. aureus. Their emerging threat comes from the fact that these bacteria can carry a large number of antimicrobial resistance genes [15], [16]. Due to the increase in antibiotic resistance in the recent years as a result of the use of these antibiotics, the World Health Organization announced a "global action plan on antimicrobial resistance" [17]. Today, the persistent, indiscriminate and inappropriate use of antibiotics and the growing spectrum of antibiotic resistance is a challenge to public health.

\section{CONCLUSION}

This study showed the incidence of Staphylococcus spp. in sewage from Manaus, Amazonas, and their susceptibility patterns to different antibiotics. May species showed sensitive and resistant strains, and the main resistance was to antibiotics of the class of $\beta$-lactamics. The indiscriminate use of antibiotics can turn commensal bacteria into multidrugresistant pathogens.

\section{ACKNOWLEDGMENT}

The authors thank the financial support from Fundação de Amparo à Pesquisa do Estado do Amazonas (FAPEAM), and Conselho Nacional de Desenvolvimento Científico e Tecnológico $(\mathrm{CNPq})$. To the scientific initiation program of the State University of Amazonas.

\section{REFERENCES}

[1] Y. Guo, G. Song, M. Sun, J. Wang, and Y. Wang, "Prevalence and Therapies of Antibiotic-Resistance in Staphylococcus aureus", Frontiers in Cellular and Infection Microbiology, vol. 10:107, 2020.

[2] W. A. McGuinness, N. Malachowa, and F. R. DeLeo, "Vancomycin Resistance in Staphylococcus aureus", Yale Journal of Biology and Medicine, vol. 90 pp. 269-281, 2017.

[3] K. M. Craft, J. M. Nguyen, L. J. Berg, and S. D. Townsend "Methicillin-resistant Staphylococcus aureus (MRSA): antibioticresistance and the biofilm phenotype" Medicinal Chemistry Communications, vol 10, pp 1231-1241, 2019.

[4] A. M. C. Hamzah, C. C. Yeo, S. M. Puah, K. H. Chua, and C.H. Chew, "Staphylococcus aureus Infections in Malaysia: A Review of Antimicrobial Resistance and Characteristics of the Clinical Isolates, 1990-2017" Antibiotics, vol. 8, 128, 2019.

[5] M. B. Said, M. S. Abbassi, P. Gómez, L. Ruiz-Ripa, S. Sghaier, C. Ibrahim, C. Torres, and A. Hassen, "Staphylococcus aureus isolated from wastewater treatment plants in Tunisia: occurrence of human and animal associated lineages". Journal Water Health, vol.15 (4), pp. 638-643, 2017.

[6] A. Zehra, R. Singh, S. Kaur, and J. P. S. Gill, "Molecular characterization of antibiotic-resistant Staphylococcus aureus from livestock (bovine and swine)", Veterinary World, vol. 10(6), pp. 598604, 2017.

[7] L. M. Sejas, S. Silbert, A. O. Reis, and H. S. Sader, "Evaluation of the quality of the antimicrobial agents disks used in disk-diffusion tests comercially available in Brazil", Jornal Brasileiro de Patologia e Medicina Laboratorial. vol.39. pp. 27-35, 2003.

[8] National Committee for Clinical Laboratory Standards-NCCLS "Performance Standards for Antimicrobial Susceptibility Testing, Twenty-Fourth Informational Supplement". NCCLS document M100S24. Wayne, PA, 2014.

[9] F. C. Cabello, H. P. Godfrey, A. Tomova, L. Ivanova, H. Dolz, A. Millanao, A. H. Buschmann, "Antimicrobial use in aquaculture reexamined: Its relevance to antimicrobial resistance and to animal and human health", Environmental Microbiology, vol. 15, pp. 1917-1942, 2013.

[10] W. L. C. Bernardo, M. F. G. boriollo, R. B. Gonçalves, J. F. Höfling, "Staphylococcus aureus ampicillin-resistant from the odontological clinic environment", Revista do Instituto de Medicina Tropical de São Paulo, vol. 47, pp.19-24, 2005.

[11] J. G. César, A. M. Peres, C. P. Neves, E. T. F. Abreu, J. F. Mello, Â. N. Moreira, and K. L. Rodrigues "Microbiological assessment of lettuce salads and antimicrobial resistance of Staphylococcus spp.", Nutrición Hospitalaria, vol. 32, pp. 2280-2285, 2015.

[12] J. Karzis, I. M. Petzer, E. F. Donkin, V. Naidoo, E. M. C. Etter, "Climatic and Regional antibiotic resistance patterns of Staphylococcus aureus in South African dairy herds", Onderstepoort Journal of Veterinary Research, vol. 86(1), a1674, 2019

[13] A. P. Basso, P. D. Martins, G. Nachtigall, S. Sand, T. M. Moura, A. P G. Frazzon, "Antibiotic resistance and enterotoxin genes in Staphylococcus sp. isolates from polluted water in Southern Brazil", Anais da Academia Brasileira de Ciências, vol. 86(4), pp. 1813-1820, 2014.

[14] Y. Cong, S. Yang, and X. Rao, "Vancomycin resistant Staphylococcus aureus infections: A review of case updating and clinical features", Journal of Advanced Research, vol. 21, pp. 169-176, 2020.

[15] C. C. Rossi, M. F. Pereira, and M. G. Marval, "Underrated Staphylococcus species and their role in antimicrobial resistance spreading", Genetics and Molecular Biology, vol. 43, e20190065, 2020 . 
[16] F. Hosseinkhani, M. T. Buirs, F. Jabalameli, M. Emaneini and W. B. van Leeuwen, "High diversity in SCCmec elements among multidrugresistant Staphylococcus haemolyticus strains originating from paediatric patients; characterization of a new composite island", Journal of Medical Microbiology, vol. 67, pp. 915-921, 2018.

[17] World Health Organization - WHO (2017) "Global action plan on antimicrobial resistance". WHO Document Production Services, Geneva. 